\title{
Double mobility cup total hip arthroplasty in patients at high risk for dislocation: a single-center analysis
}

\author{
Dominik Kaiser $^{1} \cdot$ Atul F. Kamath ${ }^{1} \cdot$ Patrick Zingg $^{1} \cdot$ Claudio Dora $^{1}$
}

Received: 12 September 2014/Published online: 29 September 2015

(C) Springer-Verlag Berlin Heidelberg 2015

\begin{abstract}
Introduction Double mobility cup systems (DMCS) have gained increasing acceptance, especially in patients at high risk for dislocation. The aim of this investigation was to analyze the frequency and indications of the DMCS use in our praxis and to evaluate dislocation and cup revision rates after a minimum follow-up of 2 years.

Materials and methods All patients implanted with a DMCS from May 2008 to August 2011 were identified from our institutional database of primary and revision THA procedures. Patient demographics, including ASA score, were recorded, along with details of the surgical procedures, indications for DMCS use, and post-operative clinical course and any complications. Radiographs were analyzed for implant positioning and radiological signs of loosening.

Results 1046 primary THA were implanted, of these 39 (4\%) primary DMCS. Indications were severe neuromuscular disease (SND) (14), hip abductor degeneration (HAD) (9), cognitive dysfunction (CD) (8) and others. 345 revision THA were performed, of these 50 (14\%) revision DMCS. Indications were recurrent dislocations (27), multiple prior hip surgeries (13), HAD (5), CD (3) and others. Overall dislocation rate was $2 / 89$ (2\%); both in revision THA. Overall cup revision rate was 5/89 (6\%): 3 septic, 1 periprosthetic acetabular fracture, 1 "intraprosthetic dissociation". 67 patients were available for the standardized questionnaire at a median follow-up of 43 months (range
\end{abstract}

Dominik Kaiser

dominik14k@gmail.com;

http://www.Balgrist.ch

1 Uniklinik Balgrist, Forchstrasse 340, 8008 Zurich, Switzerland
25-78). 19 patients were not available for two-year followup: 17 died and two were lost to follow-up.

Conclusions This study supports the use of DMCS constructs in primary and revision hip arthroplasty for specific high-risk patients. We continue to indicate DMCS in this patient group. We do caution against extending indications for DMCS to lower risk patient groups due to unknown issues surrounding wear and component longevity.

Keywords Double cup mobility system - Dislocation . Total hip arthroplasty $\cdot$ Primary $\cdot$ Revision $\cdot$ Complications

\section{Introduction}

Double mobility cup systems (DMCS) have gained increasing acceptance, especially in patients at high risk for dislocation. Dislocation rates for contemporary primary total hip arthroplasty (THA) range from 0.5 to $4.8 \%$ [1-4], while dislocation rates in revision surgery range from 7.4 to $14.4 \%$ [5-7]. Apart from factors related to surgical technique such as implant positioning and surgical approach [1-3, 8-10], patient related factors have an important influence on dislocation rates.

Potential high-risk patient characteristics are numerous, and rates of dislocation are higher than the general population. Cognitive or neuromuscular disorders carry a dislocation rate of up to $13 \%$ in the first 3 months in primary THA [11]. Female gender has been associated with a dislocation rate of $3.8 \%$ and it was $2.5 \%$ in men after 10 year follow-up [3]. Likewise, advanced age (dislocation rate of $9.2 \%$ after 1 year in patients 80 years and older [12] ) and multiple prior hip surgeries (instability rate of $4.8 \%$ in patients with prior hip surgery compared to $2.4 \%$ in primary hip surgery, with similar findings in other study 
[1, 3, 8, 10, 13-15] ) represent risk factors. Hip abductor insufficiency, with reported OR of 2.67 after a minimum follow- up of 90 days in revision THA [16] and distinctly higher dislocation rates in patients without hip abductors for revision THA for $28 \mathrm{~mm}$ heads (40 vs. $13 \%$ ) and $36 \mathrm{~mm}$ heads (33 vs. $0 \%$ ) [17], is a key risk factor. In primary THA, Woo et al. and Alberton et al. described the correlation of abductor mechanism and soft tissue tensioning in preventing dislocations [3, 6]. Poor overall health as risk factor was reported by Jolles et al.: the odds ratio of 10 was observed for dislocation in primary THA in patients with an ASA score 3 and 4 [5].

In an effort to reduce dislocation rates constrained cups have been used in high-risk patients. However, these constructs are limited by long- term failure rates of up to $26-42.1 \%[18,19]$. Failure modes, such as aseptic loosening, dissociation of the liner/cup interface, implant breakage and high polyethylene wear rates have all been reported. [18] The double mobility cup system was introduced in 1976 by Gilles Bousquet in an effort to increase stability while reducing polyethylene wear. This system consists of two different articulations: a large unconstrained bearing surface and a smaller constrained articulation. This theoretically increases ROM and the jump distance, both potentially reducing the risk of dislocation. [20] (Fig. 1). Low dislocation rates using DMCS in primary and revision THA have been reported by several independent groups [21-27]. Newer studies have diminished the former concern of excessive polyethylene wear in DMCS [28]. Further studies have shown significantly

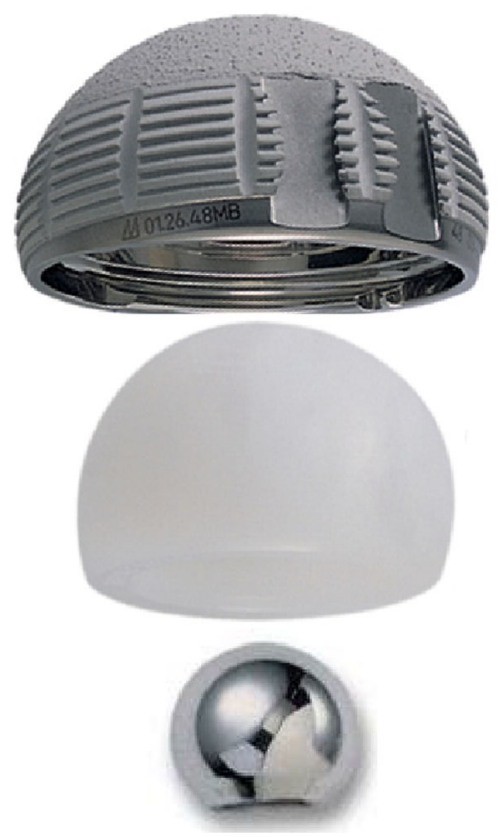

Fig. 1 DMCS Medacta ${ }^{\circledR}$ reduced polyethylene wear with the use of highly crosslinked polyethylene [29].

The use of DMCS in our department began in 2008 for primary and revision hip arthroplasty in patients at high risk for dislocation. The aim of this investigation was to test our hypothesis that dislocation rates in this high-risk patient population using DMCS would be similar to the dislocation rates of lower risk patient groups after both primary and revision THA with single-mobility THA designs. Furthermore, we sought to compare the dislocation risks with DMCS with that of the range given in the literature for primary and revision THA $[2,6]$.

\section{Materials and methods}

All patients implanted with a DMCS from May 2008 to August 2011 were identified from our institutional database of primary and revision THA procedures. Patient demographics, including American Society of Anesthesiologists (ASA) score, were recorded, along with details of the surgical procedures, indications for DMCS use, and postoperative clinical course and any complications.

A standardized questionnaire specifically asking about hip dislocation, revision surgery and antibiotic therapy was administered to all patients. Western Ontario and McMaster (WOMAC) scores were collected at least 2 years postoperatively for all patients receiving a DMCS. Complication data for the comparative group of patients receiving standard, single articulation THA implants with $28 \mathrm{~mm}$ bearings were obtained from retrospective chart review only. The primary endpoint of interest of this study was dislocation and/or cup revision for any reason.

Post-operative radiographs of the DMCS group were evaluated for implant positioning according to the safe zone as described by Lewinnek [9]. In an anteroposterior pelvis view anteversion was calculated according to Widmer [30] and inclination was measured in relation to the inter-teardrop line. On the latest available x-ray examination, radiological signs of loosening according to the system of DeLee et al. [31] were evaluated for the DMCS group.

In primary THA a direct anterior approach was used unless a hip abductor tear with tendon retraction more than $4 \mathrm{~cm}$ and/or fatty infiltration of greater than 3, using the modified Goutallier scoring system according to Zanetti et al. [32-34], was seen on MRI. In those cases, a lateral approach via tendon tear was used as described by Miozzari et al. [35], reconstructing the tendon prior to skin closure. A preoperative MRI was obtained in patients with clinical trochanteric pain syndrome and hip abductor weakness. In revision THA a direct anterior approach was used if the index approach was anterior; otherwise a posterior approach was used. 


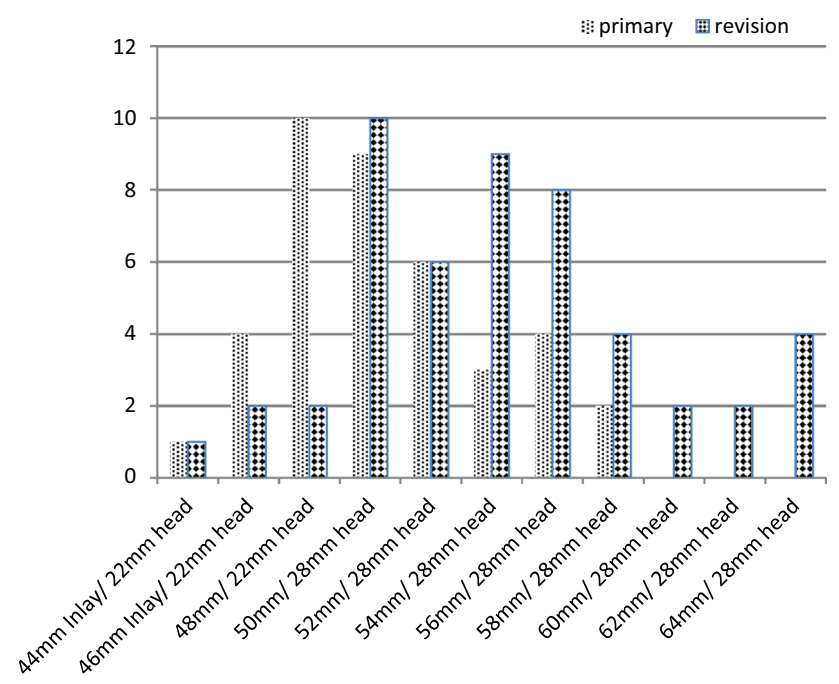

Fig. 2 Femoral head and inlay couple (diameters)

In all cases either a cemented Versacem or a non-cemented Versafit cup (Medacta International, Castel San Pietro, Switzerland) was used. If necessary an anti-protrusio cage (Ganz reinforcement ring, Zimmer Inc.,

Table 1 Indications for DMCS in primary THA
Warsaw, IN, USA) was used. Depending on intraoperative findings Quadra ${ }^{\circledR}$ stems (Medacta International, Castel San Pietro, Switzerland) or Revitan ${ }^{\circledR}$ stems (Zimmer Inc., Warsaw, IN, USA) were used.

In the primary THA group 36 Quadra ${ }^{\circledR}$ and 3 Revitan ${ }^{\circledR}$ stems were implanted. In revision THA cases 10 Quadra ${ }^{\circledR}$ stems and 10 Revitan ${ }^{\circledR}$ stems were implanted. In the remaining 30 cases the stem was not revised. The respective bearing couple diameters are shown in Fig. 2. Significantly larger cups were used in the revision THA group $(p=0.001)$. Indications for trochanteric osteotomy in primary THA were deformity of the proximal femur metaphysis (3), broken intramedullary hardware (1) and a high-riding greater trochanter (1). Indications for antiprotrusio cages in primary THA were bony acetabular defect (3) and intraoperative perforation while reaming (1). Severe hip abductor damage was defined as hip abductor tear with tendon retraction more than $4 \mathrm{~cm}$ and/or fatty infiltration of greater than 3 using the modified Goutallier scoring system [32-34].

Statistical analysis was performed using SPSS Statistics 21 package (IBM, Armonk, NY, USA). Demographic comparisons, surgery related factors and complications

\begin{tabular}{|c|c|c|}
\hline $\begin{array}{l}\text { Neuromuscular } \\
\text { disease }(n=14)\end{array}$ & $\begin{array}{l}\text { Paraplegic } \\
\text { Cerebral palsy } \\
\text { Uncontrollable epilepsy } \\
\text { Post-polio } \\
\text { Post-CVI }^{\mathrm{a}}\end{array}$ & $\begin{array}{l}5 \\
2\end{array}$ \\
\hline $\begin{array}{l}\text { Severe } \\
\text { irreversible hip } \\
\text { abductor } \\
\text { degeneration } \\
(n=9)\end{array}$ & $\begin{array}{l}\text { mod. Goutallier III }{ }^{ } \text {with MRI } \\
\text { mod. Goutallier IV }{ }^{\mathrm{b}} \text { with MRI } \\
\text { Post arthrodesis w/o MRI } \\
\text { Intraop. tear with retraction }\end{array}$ & $\begin{array}{l}1 \\
3\end{array}$ \\
\hline $\begin{array}{l}\text { Cognitive } \\
\text { dysfunction } \\
(n=8)\end{array}$ & $\begin{array}{l}\text { Trisomy } 21 \\
\text { Other }\end{array}$ & 4 \\
\hline $\begin{array}{l}\geq 3 \text { prior hip } \\
\text { surgeries }(n=4)\end{array}$ & $\begin{array}{l}\text { Posttraumatic } \\
\text { Septic } \\
\text { Sequelae of childhood disease }\end{array}$ & 1 \\
\hline $\begin{array}{l}\text { Physically } \\
\text { handicapped } \\
(n=3)\end{array}$ & $\begin{array}{l}\text { Ipsilateral above-knee } \\
\text { amputation ipsil } \\
\text { Contralateral below-knee } \\
\text { amputation }\end{array}$ & 2 \\
\hline $\begin{array}{l}\text { Morbidly obese } \\
(n=1)\end{array}$ & Body mass index $=64$ & 1 \\
\hline
\end{tabular}

${ }^{\text {a }} C V I$ cerebrovascular insult

b Analogous system using MRI

\section{6 primary}

THA

39 Double

Mobility

(4\%)

\section{7 primary THA}


were analyzed using Chi Square and Mann-Whitney $U$ tests as appropriate. The distribution of continuous variables was assessed graphically. Normally distributed data were presented as mean \pm standard deviation (SD) or mean and confidence intervals, and non-parametric data with median and range. The significance level was set to less than 0.05 .

\section{Results}

Between May 2008 and August 20111046 primary and 345 revision THA were performed at our institution. Of these 39 DMCS (37 patients) were implanted in primary and 50 DMCS (49 patients) as part of a revision THA. Indications for DMCS use are summarized in Tables 1

Table 2 Indications for DMCS in revision THA

\section{5 revision THA}

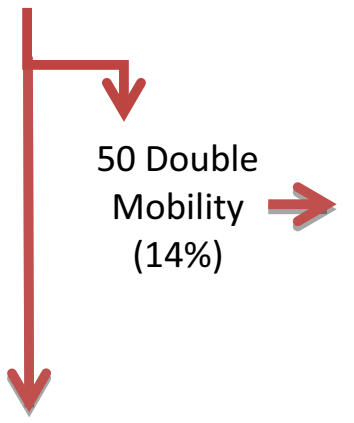

\section{5 revision THA}

a Analogous system using MRI

\begin{tabular}{|l|l|r|}
\hline $\begin{array}{l}\text { Recurrent instability } \\
(n=27)\end{array}$ & Recurrent instability & 27 \\
\hline $\begin{array}{l}\geq 3 \text { prior hip surgeries } \\
(n=13)\end{array}$ & Septic & 10 \\
\cline { 2 - 3 } & Aseptic & 2 \\
\cline { 2 - 3 } & $\begin{array}{l}\text { Ectopic ossification of hip } \\
\text { abductors }\end{array}$ & 1 \\
\hline $\begin{array}{l}\text { Severe irreversible hip } \\
\text { abductor degeneration } \\
(n=5)\end{array}$ & Goutallier III with MRI ${ }^{\mathrm{a}}$ & 1 \\
\cline { 2 - 3 } $\begin{array}{l}\text { Goutallier IV with MRI } \\
\text { a }\end{array}$ & 3 \\
\cline { 2 - 3 } $\begin{array}{l}\text { Cognitive dysfunction } \\
(n=3)\end{array}$ & Intraop. tear with retraction & 1 \\
\cline { 2 - 3 } & Bipolar disorder & 1 \\
\cline { 2 - 3 } & Undefined & 1 \\
\hline $\begin{array}{l}\text { Physically } \\
\text { handicapped }(n=1)\end{array}$ & $\begin{array}{l}\text { Ipsilateral above-knee } \\
\text { amputation }\end{array}$ \\
\hline $\begin{array}{l}\text { Neuromuscular } \\
\text { disease }(n=1)\end{array}$ & Parkinson's disease & 1 \\
\hline
\end{tabular}

Table 3 Patient demographics

\begin{tabular}{|c|c|c|c|c|}
\hline & Total DMCS $(n=89)$ & Primary THA $(n=39)$ & Revision THA $(n=50)$ & $p$ value \\
\hline Gender (female/male) & $44 / 45$ & $22 / 17$ & $22 / 28$ & n.s. ${ }^{\mathrm{a}}$ \\
\hline Age in years (range) & $66(23-92)$ & $64(23-92)$ & $73(26-90)$ & n.s. \\
\hline Body mass index (range) & $27.2(13-64)$ & $26.1(16-64)$ & $28.3(13-42)$ & n.s. \\
\hline $\mathrm{ASA}^{\mathrm{b}}$ score $\geq 3$ & 39 & 15 & 24 & n.s. \\
\hline Side (right/left) & $47 / 42$ & $23 / 16$ & $24 / 26$ & n.s. \\
\hline \multicolumn{5}{|l|}{ Surgical approach } \\
\hline Direct anterior & 33 & 26 & 7 & 0.001 \\
\hline Posterior & 33 & 0 & 33 & 0.001 \\
\hline Lateral & 8 & 8 & 0 & 0.001 \\
\hline Trochanteric osteotomy & 15 & 5 & 10 & n.s. \\
\hline \multicolumn{5}{|l|}{ DMCS cup fixation method } \\
\hline Uncemented & 58 & 32 & 26 & 0.003 \\
\hline Cemented & 12 & 3 & 9 & n.s. \\
\hline Cemented into anti-protrusio cage & 19 & 4 & 15 & 0.025 \\
\hline
\end{tabular}

a n.s. not significant $(p>0.5)$

b ASA American Society of Anesthesiologists 


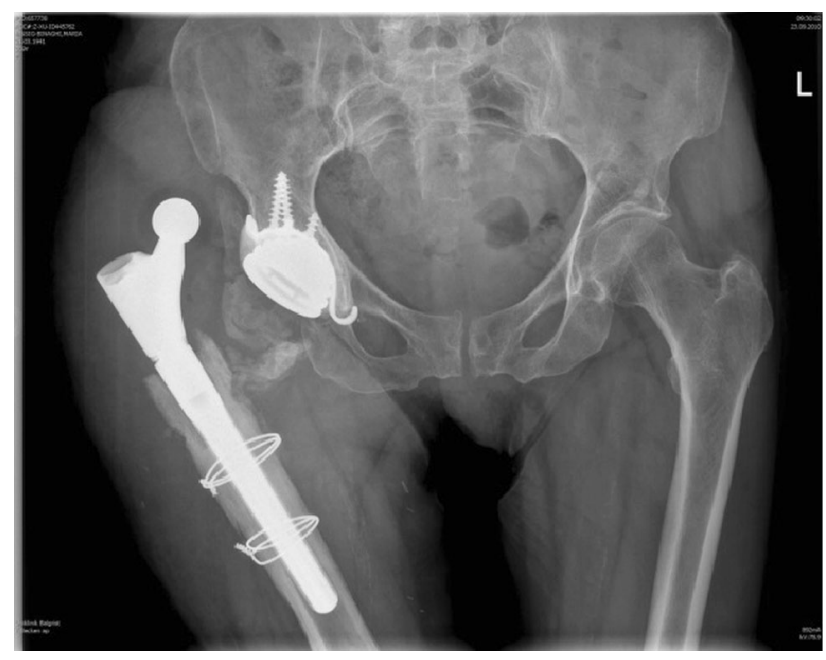

Fig. 3 Dislocation case 1, 69 years old female, indication for DMCS: Parkinson's disease, reason for dislocation: fall

and 2 for primary and revision procedures, respectively. In 17 cases, revision THA was for a septic etiology. Table 3 summarizes patient demographic variables, surgical side, approach and implants for the DMCS cohort. Significantly more posterior approaches $(p=0.001)$ and anti-protrusio cages $(p=0.025)$ were used in the revision group. In 8 primary cases, a lateral approach was used in order to repair hip abductor tears as described by Miozarri et al. [35].

Overall two dislocations occurred ( 2 of 89 cases $\hat{=} 2 \%$ dislocation rate), both in revision THA. These two dislocations were from traumatic causes after the revision procedures, and they occurred between 4 and 8 weeks after surgery. The first case was in a 69 -year-old patient with Parkinson's disease after multiple septic revisions which resulted in loss of the greater trochanter. Cup anteversion and inclination in the revision THA were $21^{\circ}$ and $40^{\circ}$, respectively (Fig. 3). The arthroplasty remained stable after open reduction. The second dislocation occurred in a 60year-old male with Trisomy 21. Cup anteversion and inclination were $23^{\circ}$ and $43^{\circ}$, respectively (Fig. 4). The arthroplasty remained stable after closed reduction. The survival rate with dislocation as an endpoint was $97.7 \%$ $(\mathrm{CI}=94.5-100 \%)$ in 75 patients after 12 months and $97.7 \%(\mathrm{CI}=94.5-100 \%)$ in 64 patients after 24 months.

During the same time period, 1007 primary THAs were implanted and 295 revision THAs were performed using standard $28 \mathrm{~mm}$ bearing couples. Dislocation rates were $0.7 \%$ (7 of 1007) in the primary THA group, and $4 \%$ (13 of 295) in the revision THA group at a minimum follow-up of 2 years.

In addition to the two dislocations; five cups were revised all after revision THAs. Three of the revisions were due to deep sepsis. One cup revision was due to a periprosthetic

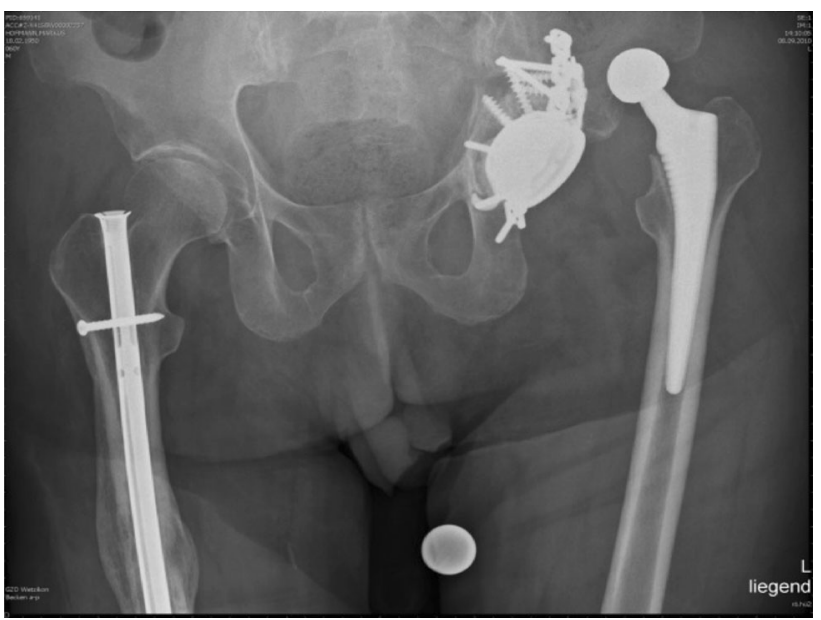

Fig. 4 Dislocation case 2, 60 years old male, indication for DMCS: trisomy 21 , reason for dislocation: fall

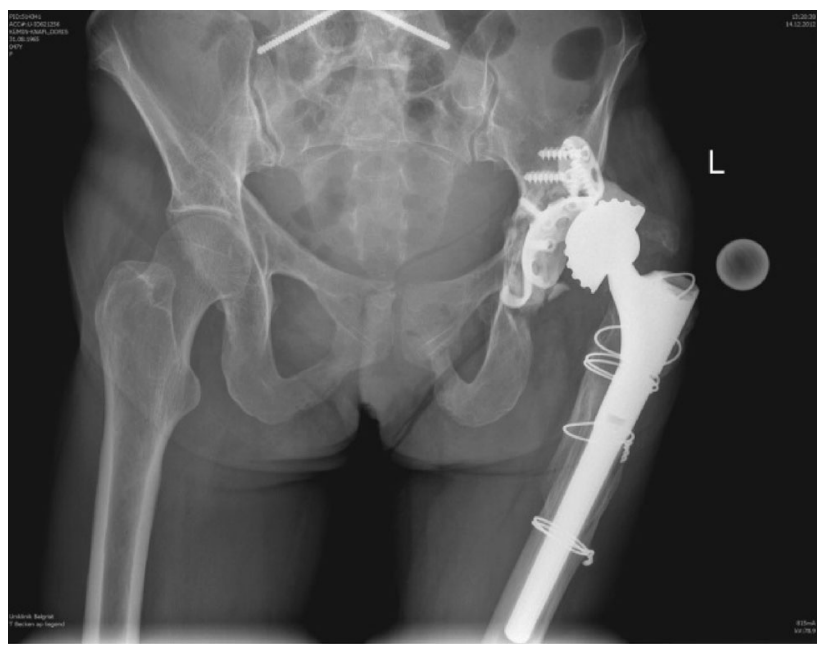

Fig. 5 Dissociation cup/anti-protrusio cage, 45 years old female, indication for DMCS: recurrent instability, reason for dissociation: unknown

acetabular fracture after a fall 4 months after DMCS implantation, and another due to dissociation of the Versacem cup from the anti-protrusio cage 2 years after surgery (Fig. 5). The survival rate with all kind of reintervention (closed reduction included) as an endpoint was $95.3 \%$ $(\mathrm{CI}=90.7-99.9 \%)$ in 75 patients after 12 months and $91 \%(\mathrm{CI}=87.7-94.3 \%)$ in 64 patients after 24 months.

Seventeen patients died at a median of 10 months (range 1-24) after index surgery. Two patients were lost to followup; they were last seen after 3 and 14 months after index surgery, respectively. At last patient contact, none of the 19 patients had sustained a dislocation or revision. Sixty-seven patients were available for the standardized questionnaire at a median of 43 months (25-78) after index surgery. 
WOMAC scores improved from 49.92 points pre-operatively to 20.16 points $[p=0.01]$ in primary THA, and from 47.04 points pre-operatively to 34.56 points at latest follow-up $[p=0.03]$ after revision THA.

No osteolysis or progressive radiolucency changes were detected at last radiologic follow-up. Implant positioning outside of the safe zone with respect to either inclination or anteversion occurred in 10 of 89 procedures $(11 \%)$.

\section{Discussion}

The aim of this investigation was to analyze the frequency of DMCS use in our practice and to evaluate dislocation and cup revision rates at a minimum follow-up of 2 years. Our hypothesis was that dislocation rates in a high-risk patient cohort managed with DMCS would not differ from the dislocation rates seen in primary and revision THA patient groups implanted with conventional, single-mobility designs and $28 \mathrm{~mm}$ bearing couples. We also sought to compare the complication rates with those experienced in the literature for primary and revision THA [2, 6], respectively.

DMCS cups were used in $4 \%$ of our primary THA, with no dislocations after a minimum follow-up of 2 years. This rate is comparable to other reports of DMCS in primary THA. Vielpeau et al. reported no dislocations after 5.2 years while Philippot et al. reported no dislocations after 10 years of follow-up [21, 22]. Both studies were performed in unselected patient groups. In contrast our study included a specific high-risk patient collective; indications for primary THA included neuromuscular disease, severe irreversible hip abductor degeneration, cognitive dysfunction, $\geq 3$ prior hip surgeries, physical handicaps and morbid obesity.

The rate of dislocation with use of DMCS in high-risk patients is also superior compared to the rate in our low-risk patient collective treated with conventional prosthesis and $28 \mathrm{~mm}$ bearings $(0.7 \%)$, especially regarding that the dislocation rate of the conventional prosthesis is most likely under-reported since dislocations treated at other hospitals are not included. We conclude that DMCS is an effective implant in minimizing dislocation in high-risk patients.

DMCS cups were used in $14 \%$ of our revision THA; indications for DMCS were recurrent instability, $\geq 3$ prior hip surgeries, severe irreversible hip abductor degeneration, cognitive dysfunction, specific physical handicaps and neuromuscular disease. This resulted in a dislocation rate of $4 \%$. In our series both dislocations occurred after a fall. An uneventful course followed after closed and open reduction, respectively. Our dislocation rates in revision THA were $4 \%$ after a minimum follow- up of 2 years; this is inferior to the $1.7 \%$ dislocation rate after 4 years followup published by Leiber et al. [27]. However, this comparison study included all patients while our study focused on high-risk patients only and may explain, in part, our higher dislocation rate. Other dislocation rates in the literature range from 3.4 to $5.5 \%$ [36, 37]. Both studies were performed in all-comers with respect to hip arthroplasty procedures.

When compared to the revision rate using conventional THA with $28 \mathrm{~mm}$ bearings (4\%), rates are comparable at our institution and distinctly lower than dislocation rates observed in the literature: i.e., $7.4 \%$ rate in a study by Alberton et al. [6], and $9 \%$ rate in a report by Kavanagh et al. [38]. We conclude that the use of DMCS in the revision procedures associated with high dislocation risk patients can avoid increased rates of dislocation.

It has been shown that larger femoral heads of a minimum of $36 \mathrm{~mm}$ are associated with a lower dislocation rate in primary and revision THA $[6,39]$. Howie et al. randomized 644 patients to receive either $28 \mathrm{~mm}$ or $36 \mathrm{~mm}$ bearing in primary THA demonstrating a significantly lower dislocation rate at 1 year for the large diameter group (0.8 vs. $4.4 \%)$, and a strong trend in patients undergoing revision THA in favor of the large diameter group (4.9 vs. 12.2) [39]. Garbuz et al. randomized patients in a $32 \mathrm{~mm}$ vs. $36 \mathrm{~mm} / 40 \mathrm{~mm}$ group; the larger head group demonstrated a significantly lower rate of instability (1.1 vs. $8.7 \%)$ at a mean of 5 years after operation [40]. Compared with the literature a comparably low dislocation rate can be achieved using larger femoral heads in an all-comers patient collective, but direct comparisons to the use of DMCS in a high-risk patient collective needs further study.

With respect to complications, one $(1 \%)$ "intraprosthetic dissociation" occurred 2 years after index surgery in the revision group. Such complications have been reported by other groups [22, 41]. Philippot suggested that younger patients and the formation of excessive scar tissue are specific risk factors for this complication.

Limitations of our study are the short radiologic followup and the high percentage of patients not available for a follow-up 2 years after index surgery mainly due to the known high mortality rate. Both of these study limitations are related to the advanced age, as well as medical and surgical morbidities associated with this high-risk patient population and revision hip surgery. Our mortality rate is comparable to the 1 year mortality rate reported in the 2013 Australian National Joint Replacement Registry annual report ranging from 5-35\% [42].

\section{Conclusion}

In conclusion, this study supports the use of DMCS constructs in primary and revision hip arthroplasty for specific high-risk patient populations. To our knowledge this is the 
first published review of DMCS in a well selected high-risk patient collective and it demonstrates that DMCS can reduce dislocation rate comparable to rates seen in conventional hip articulations, although the patient population and the indications are not directly comparable. We continue to indicate DMCS in our patients at high risk for dislocation. We do caution against extending indications for DMCS to lower risk patient groups, younger patient populations without specific risk factors for dislocation, and for those with high activity levels due to unknown issues surrounding wear and component longevity.

\section{Acknowledgments None.}

\section{Compliance with ethical standards}

Conflict of interest No conflict of interest.

\section{References}

1. Fackler CD, Poss R (1980) Dislocation in total hip arthroplasties. CORR 151:169-178

2. Hailer NP, Weiss RJ, Stark A, Kärrholm J (2012) The risk of revision due to dislocation after total hip arthroplasty depends on surgical approach, femoral head size, sex, and primary diagnosis: an analysis of 78098 operations in the Swedish Hip Arthroplasty Register. Acta Orthopaedica 83(5):442-448. doi:10.3109/ 17453674.2012.733919

3. Woo RY, Morrey BF (1982) Dislocations after total hip arthroplasty. JBJS Am 64:1295-1306

4. Berry DJ, Knoch M, Schleck CD, Harmsen WS (2004) The cumulative long-term risk of dislocation after primary charnley total hip arthroplasty. JBJS 86(1):9-14

5. Jolles BM, Zangger P, Leyvraz PF (2002) Factors predisposing to dislocation after primary total hip arthroplasty: a multivariate analysis. J Arthroplasty 17(3):282-288. doi:10.1054/arth.2002.30286

6. Alberton GM, High WA, Morrey BF (2002) Dislocation after revision total hip arthroplasty: an analysis of risk factors and treatment options. JBJS Am 84:1788-1792

7. Phillips CB, Barrett JA, Losina E et al (2003) Incidence of rates of dislocation, pulmonary embolism, and deep infection during the first six months after elective total hip replacement. JBJS Am. 85:20-26

8. Sanchez-Sotelo J, Berry DJ (2001) Epidemiology of instability after total hip replacement. Orthop Clin N AM 32(4):543-552

9. Lewinnek GE, Lewis JL, Tarr R, Compere CL, Zimmerman JR (1978) Dislocations after total hip-replacement arthroplasties. JBJS Am 60:217-220

10. Morrey BF (1997) Difficult complications after hip arthroplasty: dislocation. Clin Orthop 344:179-187

11. Woolson ST, Rahimtoola ZO (1999) Risk factors for dislocation during the first 3 months after primary total hip replacement. J Arthroplasty 14:662-668

12. Ekelund A, Rydell N, Nilsson OS (1992) Total hip arthroplasty in patients 80 years of age and older. Clin Orthop 281:101-106

13. Mahoney CR, Pellicci PM (2003) Complications in primary total hip arthroplasty: avoidance and management of dislocations. Instr Course Lect 52:247-255

14. Padgett DE, Warashina H (2004) The unstable total hip replacement. Clin Orthop 420:72-79. doi:10.1097/01.blo. 0000122694.84774.b5
15. Paterno SA, Lachiewicz PF, Kelley SS (1997) The influence of patient-related factors and the position of the acetabular component on the rate of dislocation after total hip replacement. JBJS 79A: $1202-1210$

16. Wetters NG, Murray TG et al (2013) Risk factors for dislocation after revision total hip arthroplasty. CORR 471:410-416. doi:10. 1007/s11999-012-2561-7

17. Kung PL, Ries MD (2007) Effect of femoral head size and abductors on dislocation after revision THA. CORR 465:170-174

18. Berend KR, Lombardi AV, Mallory TH, Adams JB, Russel JH, Groseth KL (2005) The Long-term Outcome of 755 consecutive constrained acetabular Components in Total Hip Arthroplasty: examining the Successes and Failures. J Arthroplasty 20(7):93-102

19. Anderson MJ, Murray WR, Skinner HB (1994) Constrained acetabular components. J Arthroplasty 9:17-23

20. Grazioli A, Teow Hin Ek E, Rüdiger HA (2012) Biomechanical concept and clinical outcome of dual mobility cups. SICOT 36:2411-2418. doi:10.1007/s00264-012-1678-3

21. Vielpeau C, Lebel B, Ardouin L, Burdin G, Lautridou C (2011) The dual mobility socket concept: experience with 668 cases. SICOT 35:225-230. doi:10.1007/s00264-010-1156-8

22. Philippot R, Adam P, Farizon F, Fessy MH, Bousquet G (2006) Survie à dix ans d'une cupule double mobilité non cimentée. Revue de chirurgie orthopédique 92:326-331

23. Langlais FL, Ropars M, Gaucher F, Musset T, Chaix O (2008) Dual mobility cemented cups have low dislocation rates in THA Revisions. Clin Orthop Relat Res 466:389-395. doi:10.1007/ s11999-007-0047-9

24. Pattyn C, De Haan R, Kloeck A, Van Maele G, De Smet K (2010) Complications Encountered With the Use of Constrained Acetabular Prostheses in Total Hip Arthroplasty. J Arthroplasty 25(2):287-294. doi:10.1016/j.arth.2008.10.010

25. Langlais F, Lissarrague M, Ropars M, Lambotte JC, Musset T, Chaix O (2005) Prothèse totale de hanche avec cupule a double mobilité scellée. Concept-Indications- Bilan de 55 cas. Ann Orthop Ouest 37:113-120

26. Stuhlberg SD (2010) Dual mobility for chronic instability: solution Option. Semin Arthro 21:45-47

27. Leiber-Wackenheim F, Brunschweiler B, Ehlinger M, Gabrion A, Mertl P (2011) Treatment of recurrent THR dislocation using of a cementless dual-mobility cup: a 59 cases series with a mean 8 years'follow up. OTSR 97:8-13. doi:10.1016/j.ostr.2010.08. 003

28. Saikko V, Shen M (2010) Wear comparison between a dual mobility total hip prosthesis and a typical modular design using a hip joint simulator. Wear 268:617-621. doi:10.1017/j.wear.2009. 10.011

29. Digas G, Kärrholm J, Thanner J, Herberts P (2007) 5- year experience of highly cross-linked polyethylene in cemented and uncemented sockets: two randomized studies using radiostereometric analysis. Acta Orthop 78:746-754. doi:10.1080/174536 70710014518

30. Widmer KH (2004) A simplified method to determine acetabular cup anteversion from plain radiographs. J Arthroplasty 19(3): 387-390. doi:10.1016/j.arth.2003.10.016

31. DeLee JG, Charnley J (1976) Radiological demarcation of cemented sockets in total hip replacement. CORR 121:20-32

32. Goutallier D, Postel JM, Bernageau J, Lavau L, Voisin MC (1994) Fatty muscle degeneration in cuff ruptures: pre- and postoperative evaluation by CT scan. Clin Orthop 304:78-83

33. Zanetti M, Gerber C, Hodler J (1998) Quantitative assessment of the muscles of the rotator cuff with magnetic resonance imaging. Invest Radiol 33:163-170

34. Fuchs B, Weishaupt D, Zanetti M, Hodler J, Gerber C (1999) Fatty degeneration of the muscles of the rotator cuff: assessment 
by computed tomography versus magnetic resonance imaging. J Shoulder Elbow Surg 8:599-605

35. Miozzari HH, Dora C, Clark JM, Nötzli HP (2010) Late repair of abductor avulsion after the transgluteal approach for hip arthroplasty. J Arth 25(3):450-457. doi:10.1016/j.arth.2008.12.010

36. Guyen O, Pibarot V, Vaz G, Chevillotte C, Béjui-Hugues J (2009) Use of dual mobility socket to manage total hip arthroplasty instability. Clin Orthop Relat Res 467:465-472

37. Saragaglia D, Ruatti S, Refaie R (2013) Relevance of press-fit dual mobility cup to deal with recurrent dislocation of conventional total hip arthroplasty: a 29-case series. Eur J Orthop Surg Traumatol 23:431-436. doi:10.1007s00590-012-1002-3

38. Kavanagh BF, Ilstrup DM, Fitzgerald RH (1985) Revision Total Hip Arthroplasty. JBJS 67(4):517-526
39. Howie DW, Holubowycz OT, Middleton R (2012) Large femoral heads decrease the incidence of dislocation after total hip arthroplasty: a randomized controlled trial. JBJS Am 94:1095-1102

40. Garbuz DS, Masri BA, Duncan CP et al (2012) The Frank Stinchfield Award: dislocation in revision THA: do large heads $(36 \mathrm{~mm}$ nad $40 \mathrm{~mm})$ result in reduced dislocation rates in a randomized clinical trial? CORR 470:351-356

41. Phillipot R, Camilleri JP, Boyer B, Adam P, Farizon F (2009) The use of a dual-articulation acetabular cup system to prevent dislocation after primary total hip arthroplasty: analysis of 384 cases at a mean follow-up of 15 years. SICOT 33:927-932. doi:10. 1007//s00264-008-0589-9

42. National Australian joint and hip arthroplasty registry: annual report 2013 